\title{
The Learning Continuum: A Model for Sustained Participation with Hard-to-Serve Clients
}

\author{
Elizabeth B. Bolton, Professor \\ Community Development \\ Department of Family, Youth and Community Sciences
}

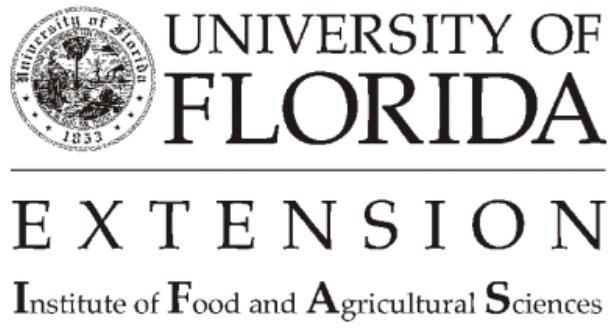




\section{WtW History}

When Congress passed the Personal Responsibility and Work Opportunity Reconciliation Act (PRWORA) in August 1996 a new era in welfare began. Reform was the keyword! Most significantly, gone was Aid to Families with Dependent Children (AFDC); gone was welfare as an open-ended entitlement either in its financing or its philosophy. Replacing AFDC was Temporary Assistance to Needy Families (TANF) and block grants. As its name implies TANF is intended to provide temporary assistance.

By law TANF benefits are restricted to a lifetime limit of five years. States may use their TANF funding in any manner that satisfies PRWORA. In Florida the legislature lowered that lifetime limit to four years. That lifetime limit and the mandated work requirements are some of the toughest in the nation. The state implemented these tough standards through the creation of public/private workforce development boards, OneStop Service Centers and contracting for services with private enterprise. The result of this ambitious program is that the welfare roles declined in Florida by 66 percent, from September 1996 to April 2000.

The TANF program has been successful. However there is a group of welfare recipients who require more than the temporary assistance initially available. This group has been called the hardest of the hard-to-serve and is labeled Welfare-to-Work (WtW), a designation by the US Department of Labor which denotes individuals with chronic welfare dependence and multiple barriers to employment. Special funds have been made available to move this $\mathrm{WtW}$ group, living in high poverty areas, from a life of government dependency to a life of unsubsidized employment and self-sufficiency. It is toward this WtW group of TANF recipients that the UF/IFAS WtW Initiative is directed.

In the1998 Florida legislative session, the University of Florida, Institute of Food and Agricultural Sciences received an appropriation of $\$ 2.5 \mathrm{M}$ to conduct educational programs for the Welfare-to-Work clientele in Florida. The Department of Family, Youth and Community Science (FYCS) was charged with conducting the project.

The goal of the WtW project is to deliver training for specific jobs that will help the welfare transition individual find and retain unsubsidized employment. In working toward the attainment of this goal, it was necessary to develop specific curricula designed for the person with educational limitations and/or barriers to learning. To date, five curricula are delivered as part of the UF/IFAS WtW armamentarium of courses for the WtW student. Another course is FastTrac First Step, a copyrighted curriculum for entrepreneurship education for the low income individual.

\section{Course Offerings}

The UF/IFAS WtW Project course offerings are listed below. Each curriculum was designed for the low income WtW student. The training materials were designed by faculty in the Department of Family, Youth and Community Sciences. Attention to the needs of the learner was the first priority with various cognitive exercises, group participation, role play, and other methods employed to stimulate and reinforce the lesson material.

JobStart: The JobStart program is designed to provide participants with a portfolio of skills related to seeking and retaining a job. Participants learn the importance of developing a positive attitude toward work, as well as the specifics of developing and implementing job search strategies. Other information essential to participants success in the workforce includes interview skills, dressing for success, preparing a resume and a cover letter, work place ethics and marketing oneself for employment. 
Elder Companion: The Elder Companion program trains participants to provide high-quality care for Florida's elder citizens. Training includes sensitivity to aging, as well as how to provide assistance with daily living activities. Home management services and the role of the home companion for older adults are also covered in the training sessions. Community-based networks will provide ongoing technical support for participants who successfully complete the program and obtain employment as elder companions. Recent studies indicate that elderly who receive less attention from nursing aides suffer more health problems and that employers have a hard time filling this type of position. This course has become one of the most popular with the participants in this project. In addition to the course, 20-40 hours of internship by the student is recommended at a hospital or nursing home. The employers like the knowledge base the WtW student brings to the work site. Many are hired and employers have accommodated the WtW graduate by sponsoring CNA training and testing. This program is currently being expanded to include "activity" modules which will assist the elderly in keeping active and maintaining small motor skills and a healthy mind.

Food Safety at the Tip of Your Fingers: This food safety training program provides participants with the essential skills for obtaining entry-level positions in the food service industry. Though not a cooking course, topics covered during training include safe food storage, safe cooking and handling practices, personal hygiene in the food service industry work place, and proper cleaning and sanitizing procedures. Continued growth in Florida's hospitality industry provides opportunities for those who successfully complete Food Safety training. All Instructors are certified to award the Florida Food Handler's Certification, which is required by law. This will only be used in conjunction with the $\mathrm{WtW}$ student as part of the curriculum to assist them in obtaining unsubsidized employment. An internship of 20-40 hours is recommended for the food safety student at a hospital, nursing home, upscale cafeteria or restaurant and other food service sites such as school cafeterias or soup kitchens.

Planting the Seeds for Success: This horticulture training program prepares participants for entry-level positions in nurseries, home garden centers and grounds maintenance. Training includes plant handling, water management, insect identification, plant propagation and safety skills. The need for semi-skilled labor in the agriculture industry provides diverse opportunities for participants who successfully complete the program.

A Green Future: This horticulture training program prepares participants for entry-level positions in grounds maintenance. In addition, the participant will develop the skills and practices necessary to provide lawn care service. Training includes plant handling, water management, insect identification, plant propagation and safety skills. Participants will gain the background necessary for future employment at resorts; golf courses or contract lawn care services, as well as for opportunities for self-employment.

Entrepreneurship Education-FastTrac First Step: FastTrac First Step is a nationally recognized training program that covers the entry strategies for small start-up businesses and is designed for the low income student. Participants will identify business opportunities; develop a concept; research and test the market for acceptance and pricing; and develop a feasibility plan for launching the new venture. Upon completion of the program, students will have a written feasibility plan that is based on their personal aspirations for starting a small business. At the January, 2001 In-service training, one of the developers of this course trained all the project staff to teach this highly specialized course offering. The First Step Fund, Entrepreneurial Education Foundation, Center for Entrepreneurial Leadership Inc. at the Ewing Marion Kauffman Foundation, Kansas City, Missouri, supports the efforts of the WtW Project in presenting this curriculum to the low income population of Florida.

\section{Linear Instruction}

Under the original concept of linear instruction each course was a stand-alone program with all students entering one course at the same point. The stand-alone nature of the courses afforded both limited utility and flexibility in dealing with the "hardest to serve" students (those with multiple barriers). However, the courses held significant 
merit because of the "hands on" approach to instruction of the classes developed by UF/IFAS. (See Figure 1.)

\section{Linear Instruction}

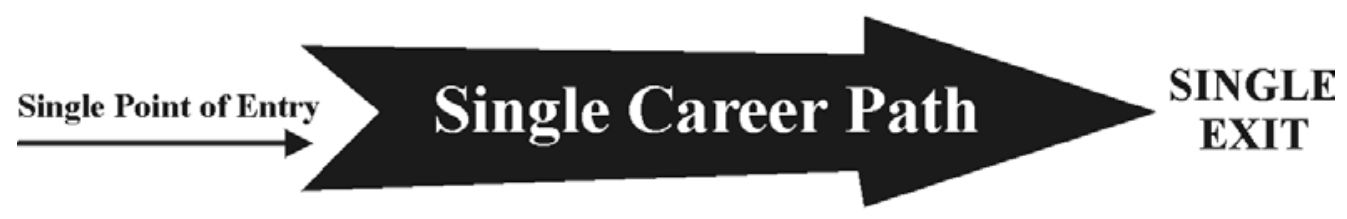

\section{- All courses are stand alone - Students enter one course at same}

Figure 1.

Class size was not a barrier to instruction. Rarely would a class exceed seven students. Instructors were directed to teach a course upon request from the OneStop. As soon as a OneStop career manager identified someone interested in one of the UF/IFAS course offerings, a course was scheduled and the career managers would actively search for additional students. Occasionally the course would only have a single student.

The UF/IFAS courses were all stand alone. There were no prerequisites for attending any of the courses nor was advance study available through the OneStop or UF/IFAS. An interest in the subject matter and concurrence by the career manager was all that was required for enrollment. On occasion a student would sign up for a course solely because he was required to be enrolled in an accountable activity to collect his cash subsidy; and going to school was easier in some cases, than looking for a job. The student would complete the course and receive the UF/IFAS Course Completion Certificate and the career manager would indicate in the individual records that the student was compliant with state and local requirements. Consequently, the student would remain eligible to receive cash assistance. While the $\mathrm{WtW}$ instructor would follow-up with the student and assist with employment opportunities, the student received no incentive from the OneStop to actively make use of the training or instructional material as a vocation.

All UF/IFAS courses were structured learning, not open entry/open exit. The open/open course structure, as were so many other courses designed for this student group, would allow the student to enter the course at any point in the instruction and exit upon desire or assumed need. As practiced by the OneStops, open/open allowed the student to use class time for appointments other than educational requirements. Consequently, students habitually scheduled doctors appointments or automobile maintenance during the time they were supposed to be in class, as opposed to during their free time. The structured learning concept required the student to begin the course on Monday at the appropriate time, to be at class daily and on time, and to schedule any appointments for a time other than class time. While attendance was not perfect, there was only an approximate twenty percent drop out rate. A lot was expected from the $\mathrm{WtW}$ student, and they generally responded in a positive manner.

All students would leave the course and exit at the same time. They must have completed the UF/IFAS required number of hours for the course to receive the certificate. "Graduation" ceremonies were conducted and the UF/IFAS Certificates of Completion were presented. The grant did not allow for the purchase of food, drinks, snacks or cakes. However the WtW instructors were ingenious and usually put together a celebration at little or no cost to anyone. Guest speakers were invited to pass out certificates, shake hands and expound on the value of their training and the virtues of working toward self-sufficiency. On more than one occasion, a Friday graduation 
ceremony for two students resulted in an audience of over twenty onlookers dressed in their Sunday best, including spouses/significant others, mothers/fathers, grandmothers/grandfathers, children/grandchildren, ministers and others. Suddenly the drop out who never had finished anything, did indeed complete something and showed they could be successful.

Each of the UF/IFAS courses were stand alone. There was no prerequisites for entering and advance course offerings were not readily available through the OneStop system or UF/IFAS. The UF/IFAS WtW grant was to provide entry level instructional training courses only. The WtW instructors would assist the student with finding a job when possible, but the barriers to employment, not always identified and exhibited, stunted growth and employment potential. When the course was over the student disappeared in most cases and the WtW instructor had a difficult time providing any practical follow-up.

This linear approach to instruction resulted in a high level of success and course completion rate by WtW students; however an inordinate number of students could not maintain acquired employment for an extended period of time. The WtW student would obtain employment only to be out of work in three to five weeks. Why, what was the problem? How much skill did it require to work an entry level, non-technical position?

Upon reviewing the WtW student employment patterns, it was determined that the curriculum provided the student with sufficient entry level skills to obtain and maintain employment under normal conditions. Additionally Regional Workforce Board (RWB) OneStop career managers worked closely with the student to eliminate recognizable barriers to employment (child care, transportation issues, etc). What was not being addressed was basic education, a high school diploma or GED which was required for many good jobs, and individual self-esteem. The student group being taught was predominately women who had dropped out of school around the age of 16 due to a pregnancy and who had a history of not completing anything significant. The student group as a whole had been told by family and friends that they were quitters, that they were worthless. As individuals they had no self-value, no self-esteem. To build self-worth, a new concept was necessary and education, success and the GED were the keys.

\section{Learning Continuum}

A new Learning Continuum program design replaced the linear nature of the stand-alone classes with a circular approach that has come to be known to the WtW student as "The Wheel to Success." (See Figure 2.) In the Learning Continuum concept, the focus of the program and the hub of the wheel is the completion of the GED rather that the completion of individual courses. Many students completing the UF/IFAS courses were unsuccessful in their employment search despite their classroom success because they lacked a GED, which was necessary for many employment opportunities. Also, while many of the students had successfully completed a single course, they still lacked the depth of life/career skills and confidence necessary for them to acquire and retain employment. As a result, the UF/IFAS courses are placed in a continuous loop. Rather than each course being an end in itself, the courses become the core of a larger continuous program that ultimately leads to a GED, greater self-esteem and better work ethics. The Continuum concept offers open entry and open exit between any course and into the loop. The courses themselves are structured, not open entry. Each course is an integral part of a larger whole concept. The focus is no longer on the individual course, but on the individual developing career/life skills and on obtaining a GED. A full time GED instructor is necessary and should be readily available to provide hands on direction and educational support during the weeks the customer is not engaged in UF/IFAS training.

While the Learning Continuum itself is open entry/open exit, the courses remain structured. A student may enter the Continuum at any point on the wheel and begin the evaluation and testing part of the process. The actual UF/IFAS class work portion of the process remains structured. All courses begin on a Monday and the student is expected to be at class every day, on time and prepared. 


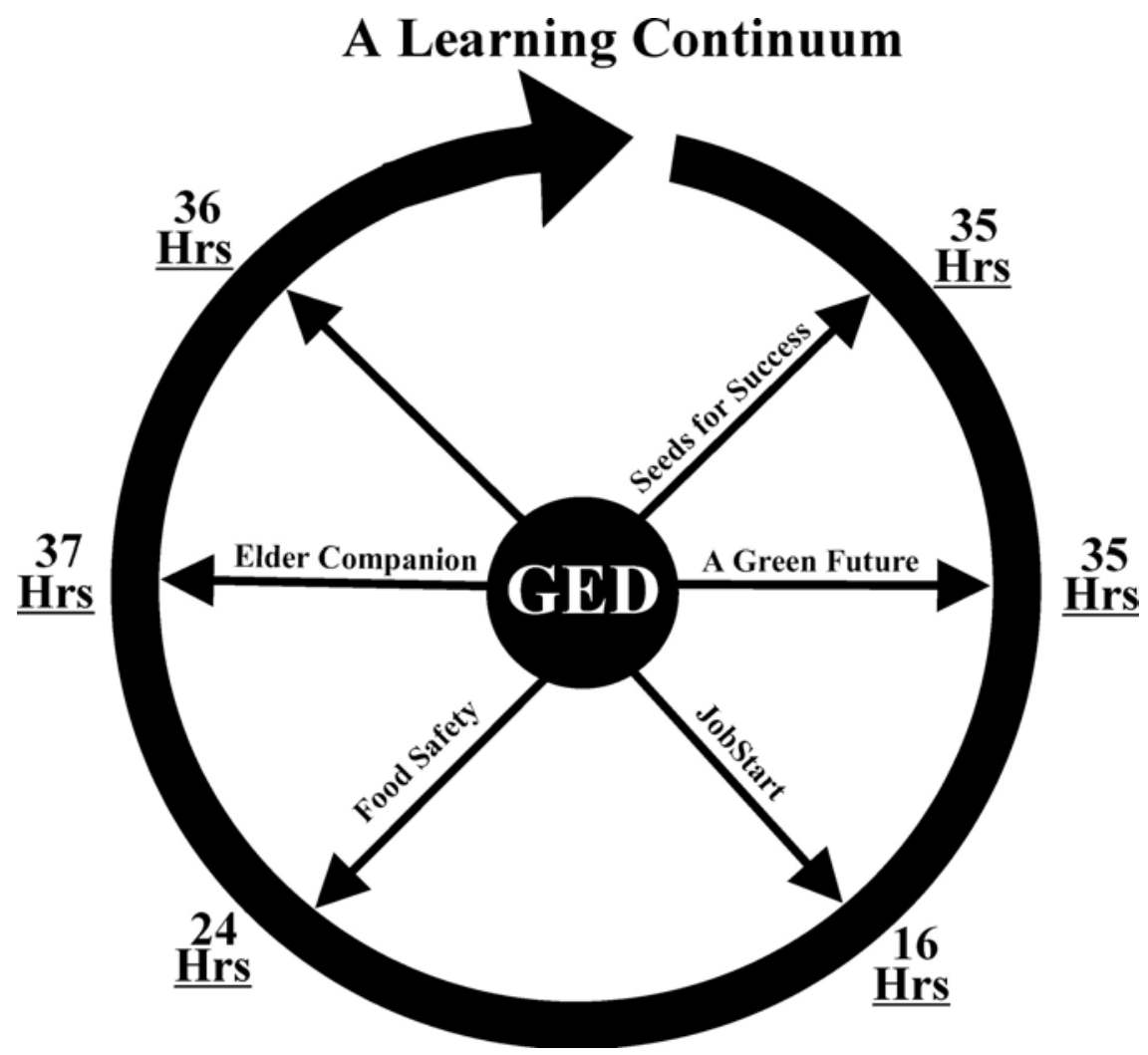

- Courses are part of a continuous loop

- Open Entry and Open Exit into program

- Courses are structured learning

- Each course is a part of a larger whole concept

- Focus is no longer on only the course, but on developing career/life skills and obtaining GED

Figure 2.

At the successful conclusion of each course offering individual course Certificates of Completion continue to be awarded to acknowledge success and build self-esteem. "Graduation" ceremonies are conducted as before. With each certificate the student is rewarded with a feeling of success and personal satisfaction.

A common thread through each of the UF/IFAS courses is developing career/life skills, work ethics, and obtaining a GED. The WtW student has a requirement from the state to be engaged in accountable activities for 30 hours weekly. These accountable activities may include job search, training, counseling or other pursuits as defined by the PRWORA. At the conclusion of each UF/IFAS class day, the student is referred to the GED lab where they receive hands on attention and continue to satisfy their 30 hour state requirement.

The Learning Continuum only works with the support of the RWB and the OneStop service provider. It creates a partnership in which the UF/IFAS instructor works closely with the RWB and OneStop to ensure the success of the $\mathrm{WtW}$ student. The UF/IFAS courses are set up on a rotating basis and a different course is scheduled every other week. This allows the RWB and OneStop to ensure the student is making progress and maintains a positive attitude.

The RWB integrates its areas of expertise (assessment, testing, counseling and remediation) into the design. By providing assessment and testing prior to the enrollment into the UF/IFAS courses and again at the conclusion of each UF/IFAS course, a solid baseline of data is compiled which facilitates counseling and targets weak areas requiring remediation. This integrated learning approach promotes success. At the completion of the program, UF awards a Certificate of Accomplishment encompassing the entire range of course offerings. More importantly, the student is equipped with extensive life/career skills and practical work experiences as well having earned and 
receiving their GED. (See Figure 3.)

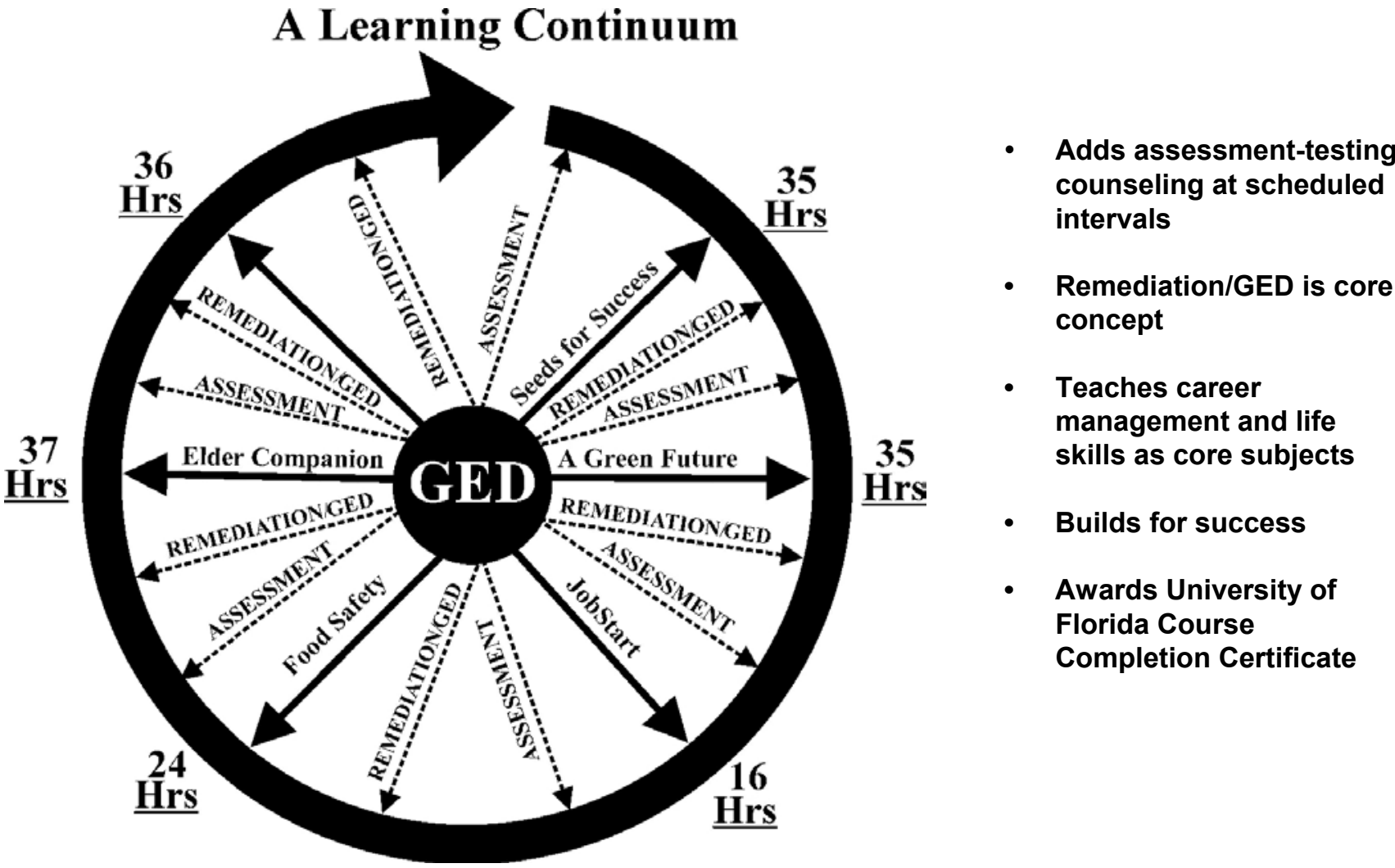

Figure 3.

Assessment begins with enrollment into the state computer system and one-on-one interviews with counselors at the OneStop. Counseling and evaluation by the OneStop professionals continue throughout the duration of the Continuum to determine barriers and limitations to employment. Prior to enrollment into any UF/IFAS course, the $\mathrm{WtW}$ student is tested to determine current abilities. These tests may include Career Scope, CHOICES, the TABE, or other employability aptitude test as deemed appropriate or necessary. Additionally the RWB initiates physicals, background checks and drug tests on everyone entering the Continuum. Because background checks, drug tests and physicals are required before entering certain career fields, completing these checks and tests make the $\mathrm{WtW}$ student more desirable to the employer.

Hands-on remediation, intense counseling, and GED classes are conducted by the RWB during the weeks when UF/IFAS courses are not being offered. As with the structured training provided by UF/IFAS, life skills and social values are continually stressed to build upon the success the WtW student is having in the classroom. Sessions are held to identify and eliminate barriers to employment and success; many of those barriers have not previously been recognized. As the student becomes more successful, he begins to identify his own needs, not just physical needs but emotional needs as well.

Perhaps the best part of the Learning Continuum is its flexibility and ability to meet the needs of the WtW student and the RWB. The RWB provides counseling, remediation, GED instruction, and testing. The UF/IFAS WtW team provides entry level training in different skill areas. Although the education curriculum reflects those courses currently offered through UF/IFAS, additional short term training curricula can be developed to reflect the workforce needs of the Workforce Board. In addition, the program design can be modified as needed. It should be noted that when implementing the Continuum concept, the needs of the WtW student is the driving 
factor rather than time. Some students with severe learning or emotional dysfunctions require extended time in the Wheel.

A WtW student enrolled in this program would receive over 270 hours of structured and RWB accountable activities that will lead to the award of the GED and a UF/IFAS Certificate of Accomplishment. The RWB then works with the student to obtain a job and provides on-going focused case management to assure retention. Once employed the students are tracked and may well become prime candidates for career progression through the Incumbent Worker Training Program funded by the state.

Early indicators show that the Learning Continuum has unlimited potential. The students, who have completed the cycle, have walked away with a sense of accomplishment and a new view of themselves as an important part of their community. They have gained success, value, and self-esteem. They have been more diligent in seeking permanent employment. And once employment is found the WtW student has exhibited outstanding work ethics.

\section{Benefits to the WtW Clients of Florida}

The adaptation of the Learning Continuum supports the WtW clients of Florida in transition from a lifetime of dependency to self-sufficiency. The Continuum provides the opportunity and the means for this student group to re-enter mainstream society. Education is the means to change ones social status. But without the opportunity to change ones mind-set, the WtW student finds it difficult to climb off of government subsidies. The Learning Continuum provides the $\mathrm{WtW}$ student with the chance to obtain self-esteem, success and to build work ethics which will last a lifetime.

\section{Benefits to UF/IFAS}

The adaptation of the Learning Continuum throughout the state is consistent with the IFAS Vice President's program of Florida FIRST. It serves the people of Florida and increases the visibility of IFAS with the constituency of Florida.

The Continuum allows IFAS the opportunity to develop and utilize new educational offerings. This is a unique student group with unique requirements which differs from area to area. While a high school diploma is normal in some parts of Florida, some areas in the panhandle have a literacy rate of less than $43 \%$. The needs of the local area is the driving force of the Continuum. This concept allows for the development of curriculum specifically directed toward the student of a particular area, region or county, which makes the individual more employable and productive. Programmatic partnerships are developed through the Continuum concept. The Regional Workforce Boards (RWB) are comprised of public and private community leaders. The adaptation of this concept provides an opportunity to disseminate accurate, positive information concerning IFAS, to the civic and business leaders of the community which widens the visibility of UF/IFAS.

The Learning Continuum allows IFAS the opportunity to enhance the utilization of current resources. The County Extension Offices have a cadre of highly trained professionals who are dedicated to making the lives better for those they support. This concept provides for an expanded area and student group for program delivery.

This report, The Learning Continuum: A Model for Sustained Participation with Hard-to-Serve Clients, is part of the UF/IFAS Welfare-to-Work Initiative (Grant \#A6218) funded by the Florida Agency for Workforce Innovation (formerly Florida Department of Labor and Employment Security). The Principal Investigator is Elizabeth B. Bolton, Professor of Community Development, Department of Family, Youth and Community Sciences. 